\title{
A Planar Antenna on Flexible Substrate for Future 5G Energy Harvesting in Malaysia
}

\author{
A. K. M. Zakir Hossain ${ }^{1}$, Nurulhalim Bin Hassim² \\ S. M. Kayser Azam ${ }^{3}$, Md Shazzadul Islam ${ }^{4}$, Mohammad Kamrul Hasan ${ }^{5}$ \\ Centre for Telecommunication Research and Innovation (CeTRI), Fakulti Teknologi Kejuruteraan Elektrik and Elektronik \\ (FTKEE), Universiti Teknikal Malaysia Melaka (UTeM), Melaka, Malaysia ${ }^{1,2}$ \\ Department of Electrical and Computer Engineering, International Islamic University Malaysia, Kuala Lumpur, Malaysia, \\ Center for Cyber Security, Faculty of Information Science and Technology, The National University of Malaysia \\ Kuala Lumpur, Malaysia ${ }^{5}$
}

\begin{abstract}
This article presents a planar monopole antenna on flexible substrate for middle band $5 \mathrm{G}(3.5 \mathrm{GHz})$ application in Malaysia. The antenna has been designed and optimized for its gain and efficiency with an improved performance in contrast of flexible substrate-based other antennas. The antenna resonates at 3.53 GHz and it has a -10dB bandwidth of $545 \mathrm{MHz}$. The bending effects of this antenna on the $S$-parameter and gain have also been investigated. The antenna is able to suppress all the other frequency bands until $20 \mathrm{GHz}$. The designed antenna has been utilized with a newly designed rectifier to act as an rectenna at 3.5 GHz for RF energy harvesting applications. A reasonable amount of DC output voltage of $930 \mathrm{mV}$, and a Power Conversion Efficiency of $\mathbf{4 3 . 5 \%}$ have been obtained while $0 \mathrm{dBm}$ RF input power is delivered to the rectifier input terminal. Apart from the utilization as an energy harvester being connected with the proposed rectifier, the designed antenna on flexible substrate can also be employed to biomedical and sensor applications.
\end{abstract}

Keywords-Planar monopole; flexible substrate; 3G; bending effect; rectenna; $R F$ rectifier; energy harvesting

\section{INTRODUCTION}

According to the recent allocation of $5 \mathrm{G}$ by Malaysian Communications and Multimedia Commission (MCMC) for mobile broadband services, three different frequency bands of $700 \mathrm{MHz}, 3.5 \mathrm{G} \mathrm{Hz}$, and $26 / 28 \mathrm{GHz}$ are going to be utilized for future $5 \mathrm{G}$ applications [1]. The end users are expecting a shuttle change in the wireless telephony and access to the internet with the possible implementation of $5 \mathrm{G}$ which will enable many precise and automated applications such as IOT, biomedical sensing, energy harvesting, automated agriculture etc. [2]. Expecting a paradigm shift, all these applications are in the pipeline for the researchers to explore further by utilizing the power of 5G. Since an antenna is the main getaway for any radio frequency (RF) to any device, it will play a major role in the successful establishment of 5G. Also, an antenna is the frontline component to improve the energy harvesting for $5 \mathrm{G}$.

Antennas on rigid substrates (PCB) are comparatively better in gain performance. However, for the applications like wearable biomedical devices/body area network (BAN) devices, microwave sensing devices, rigid antennas are not fully suitable because of their inflexibility. In [3], a dipole rectenna is proposed on the flexible substrate for the energy

This research is partially sponsored by the Center for Research and Innovation (CRIM), Universiti Teknikal Malaysia Melaka (UTeM), Melaka, Malaysia harvesting application [3]. An array is designed for the rectenna to harvest the $\mathrm{RF}$ energy from $7 \mathrm{GHz}$ to $12 \mathrm{GHz}$ frequency band. However, the dimension of the antenna is large in size. A planar double monopole antenna on the paper substrate is proposed in [4] for RF energy harvesting within the $2.45 \mathrm{GHz}$ ISM band. The antenna exhibits a good gain of $4 \mathrm{dBi}$; however, the antenna dimension is very large around $\left(60 \times 30 \mathrm{~mm}^{2}\right)$. A planar slotted-ring antenna is proposed in [5] which also works for $2.45 \mathrm{GHz}$ ISM band. The antenna is realized on the transparent polyethylene terephthalate (PET) substrate which has a dimension of $27.2 \times 25.5 \mathrm{~mm}^{2}$ with a $2.4 \mathrm{dBi}$ directive gain. Recently, a CPW-fed monopole antenna is proposed on the PET substrate in [6] for energy harvesting applications with the future $5 \mathrm{G}$ network at 3.5 $\mathrm{GHz}$. The antenna exhibits a good efficiency at $3.5 \mathrm{GHz}$ yet suffers with a low realized gain of $1.51 \mathrm{dBi}$.

As important as the antennas, the rectifiers are also the essential part of the RF energy harvesting system. In [7] the authors have proposed an antenna-rectifier (rectenna) from $900 \mathrm{MHz}$ to $3 \mathrm{GHz}$ having band notches at ISM and WLAN applications. The antenna has been designed on a thin flexible and transparent substrate named poly-methyl methacrylate (PMM) and the structure is circular loop in nature. The operating frequencies are $940 \mathrm{MHz}, 1.86 \mathrm{GHz}, 2.14 \mathrm{GHz}$, and $2.49 \mathrm{GHz}$ respectively for different application such as GSM (900 and 1800) and LAN. Still, the dimensions are large and the results show that the antenna works well in the lower frequency due to the largeness of the structure. In [8] the authors have utilized a spiral antenna for energy harvesting at GSM 1800 (1.7 GHz to $1.9 \mathrm{GHz})$ with a RF/DC converter (a voltage doubler) with a Schottky diode HSMS2850. Due to the larger size of the antenna $\left(800 \times 900 \mathrm{~mm}^{2}\right)$, the realized measured gain is comparatively high around $7 \mathrm{dBi}$. However, the efficiency of the whole rectenna system is very low as $0.6 \%$. Recently another planar microstrip DGS antenna has been proposed in [9] to harvest the RF energy between $1 \mathrm{GHz}$ to $5 \mathrm{GHz}$. The antenna as has a decent size of $45 \times 41 \mathrm{~mm}^{2}$. However, the proposed antenna has a small realized gain of only $2.7 \mathrm{dBi}$.

In this work, a monopole antenna has been designed and integrated with a new rectifier to improve the antenna gain and the power conversion efficiency (PCE) without any distinct impedance network between the antenna and the rectifier. 
Until $20 \mathrm{GHz}$, no resonance is offered by the designed antenna which contributes to reduce the obligatory use of output filter for the rectenna. Antenna design is described in Section II, and rectifier design is explained in Section III. The overall performance analysis of the proposed rectenna is discussed in Section IV.

\section{ANTENNA DESIGN}

The antenna designed here is a keyhole-shaped microstrip planar antenna with partial ground plane. The substrate used here is Kapton $\mathrm{HN}$ with a dielectric constant of $\varepsilon_{r}=3.5$, height $(h)$ of $0.125 \mathrm{~mm}$ and the loss tangent $(\tan \delta)$ of 0.001 . The full 3-D simulator CST MWS 2019 has been used for the design and simulation. Fig. 1 shows the design structure of the antenna.

The antenna design steps can be seen from Fig. 2. At first, a rectangular patch has been designed with $6.8 \times 6.8 \mathrm{~mm}^{2}$ dimension. After that, a circular patch is modeled and centered at the middle point of the top arm of the rectangle with a radius of $6 \mathrm{~mm}$ to make is as a keyhole shape. A feedline of $12.8 \mathrm{~mm}$ length is then connected to make it a microstrip feedline. The ground plane is reduced to $9 \mathrm{~mm}$ length with the same width of the total antenna structure to make the partial ground plane (PGP) structure. The final dimension of the antenna is $27.4 \times 15.6 \mathrm{~mm}^{2}$.

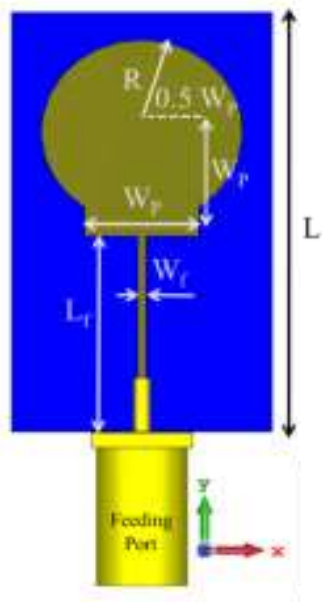

(a)

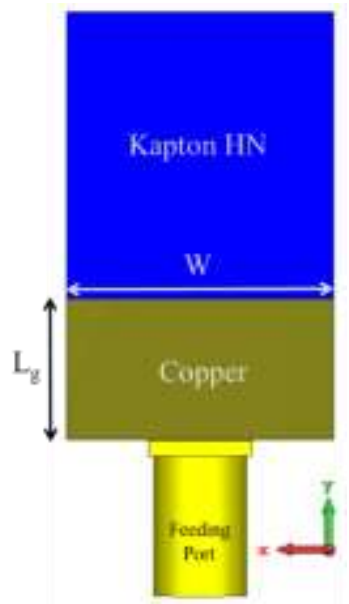

(b)
Fig. 1. Planar Keyhole-Shaped Antenna Design (a) front view and (b) back view $\left(L=27.4 \mathrm{~mm}, W=15.6 \mathrm{~mm}, L_{f}=12.8 \mathrm{~mm}, L_{g}=9 \mathrm{~mm}, W_{p}=6.8\right.$ $\mathrm{mm}, R=6 \mathrm{~mm}$, and $\left.W_{f}=0.5 \mathrm{~mm}\right)$.

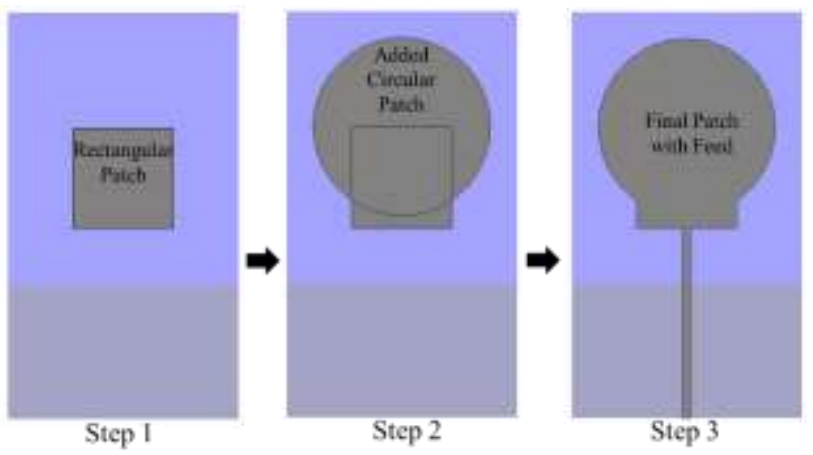

Fig. 2. Three Steps of the Antenna Design.
The antenna dimensions have been estimated by the equations as follows [10], [11]:

$\varepsilon_{e f f}=\frac{\varepsilon_{r}+1}{2}+\frac{\varepsilon_{r}-1}{2}\left[1+12 \frac{h}{W_{p}}\right]^{-\frac{1}{2}}$
$L_{e f f}=\frac{c}{2 f_{r} \sqrt{\varepsilon_{e f f}}}$
$\Delta L=0.412 h \frac{\left(\varepsilon_{e f f}+0.3\right)\left(\frac{W_{p}}{h}+0.264\right)}{\left(\varepsilon_{e f f}-0.258\right)\left(\frac{W_{p}}{h}+0.8\right)}$

$L_{p}=L_{e f f}-2 \Delta L$

Where, $\varepsilon_{e}$ is the effective dielectric constant, $L_{e}$ is the effective length of the patch, $C_{0}$ is the speed of the light at vacuum, and $\mathrm{f}_{\mathrm{c}}$ is the resonant/center frequency. Length $\left(L_{g}\right)$ and width $\left(W_{g}\right)$ of the PGP have been calculated from (5) and (6), respectively.

$L_{g}=6 h+L_{p}$

$W=W_{g}=6 h+W_{p}$

The radius ( $r$ ) of the circular patch has been approximated by (7) and (8) as follows [12]:

$r=\frac{F}{\left\{1+\frac{2 h}{\pi \varepsilon_{r} F}\left[\ln \left(\frac{\pi F}{2 h}\right)+1.7726\right]\right\}^{\frac{1}{2}}}$
$F=\frac{8.791 \times 10^{9}}{f_{c} \sqrt{\varepsilon_{r}}}$

\section{RECTIFIER DESIGN}

Conventionally, an RF rectifier is connected to the antenna through an impedance matching network which sometimes adds more loss of the input RF signal coming from the antenna. Thus, the overall PCE can be decreased. To avoid such a possibility of losing some PCE, a voltage doubler topology-based new RF rectifier has been proposed in this work which omits the need of the impedance matching network between the rectifier and the antenna to construct the complete rectenna circuit. Fig. 3(a) demonstrates a topological circuit of the rectenna, and Fig. 3(b) shows the final layout of the proposed rectifier.

Two Schottky diodes with the model of SMS7630-079LF, and two capacitors of $1000 \mathrm{pF}$ have been utilized to construct the voltage doubler circuit. The core of the proposed rectifier has been designed with transmission lines of 1.14 times higher impedance than that of the RF feedline. To avoid sudden rise of impedance after the feedline which can be potentially threatening to increase the return loss [13], [14], a tapered transmission line has been employed from lower to higher impedance. As depicted in Fig. 3(b), Tapered Line 1 of about $\lambda / 60$ length is connected between the feedline and the rectifier core. On the other hand, to serve the purpose of DC feed, a longer tapered line has been connected between the rectifier core and the output terminal. As seen in Fig. 3(b), Tapered Line 2 of about $\lambda / 12$ length has been utilized to perform like the DC feed. Because the rectifier output terminal needs to block the RF signal as much as possible, Tapered Line 2 is 
ended with 2 times higher impedance line than that of the RF feedline. In other words, impedance of the output DC line is 1.75 times higher than that of transmission lines of the rectifier core. Such a gradual rise of impedance at the two terminals of the rectifier core provides more stability while the rectification process is performed. As a result, a better PCE can be achieved by the following equation:

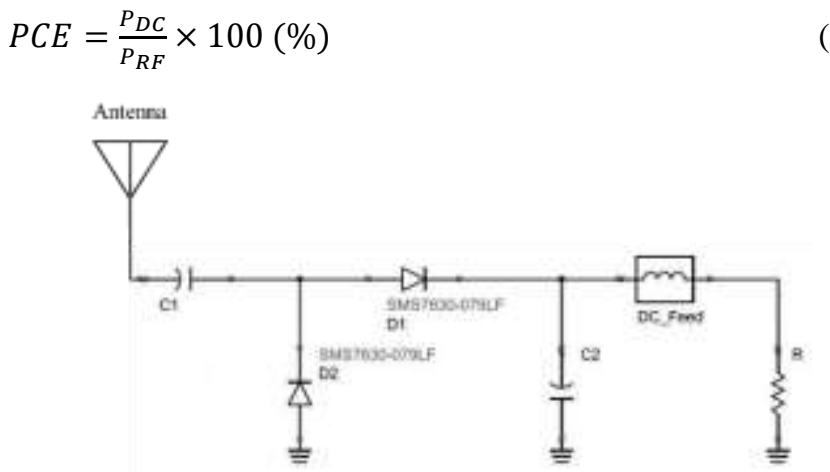

(a)

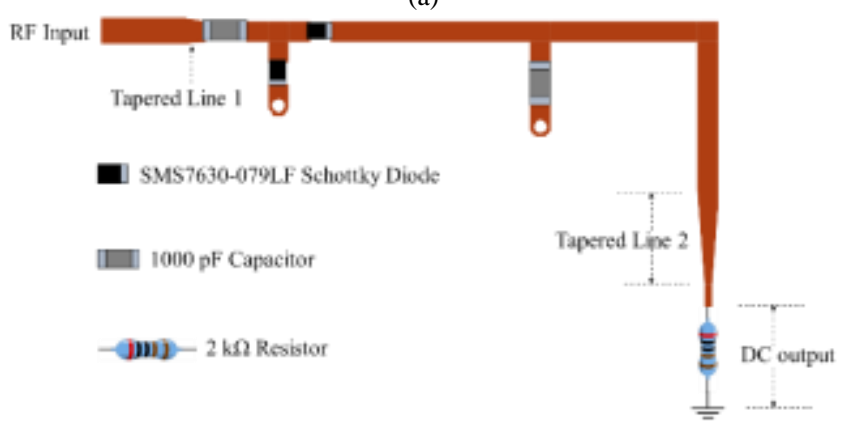

(b)

Fig. 3. Proposed Rectifier (a) Topological Circuit of the Rectenna (b) Final Layout.

The rectifier has been designed and simulated by utilizing manufacturers' spice models with the design tool-kit and electromagnetic simulator of Advanced Design System (ADS) 2017. The design, optimization and simulation have been performed by considering the DC load resistor as $2 \mathrm{k} \Omega$, and the center frequency as $3.5 \mathrm{GHz}$.

\section{RESULTS AND DISCUSSIONS}

\section{A. Antenna}

Fig. 4 shows the S-parameter $\left(S_{11}\right)$ and VSWR responses of the designed planer antenna. Fig 4(a) depicts a wide-span response of the designed antenna until $20 \mathrm{GHz}$. It is seen that the antenna has resonance only at $3.53 \mathrm{GHz}$ between $1 \mathrm{GHz}$ and $20 \mathrm{GHz}$. It clearly demonstrates that other frequency bands are suppressed by the designed antenna. Fig 5(b) shows the exploded view of the $S_{11}$ response of the antenna between $3 \mathrm{GHz}$ and $4 \mathrm{GHz}$. It is seen that the antenna has the $S_{11}$ value as low as $-22.5 \mathrm{~dB}$ at $3.53 \mathrm{GHz}$ and the $-10 \mathrm{~dB}$ bandwidth (BW) is around $545 \mathrm{MHz}$. To justify the resonance further, Fig. 5(c) also shows the VSWR response of the antenna. As expected, it also shows that the value is below 2 for the entire BW of the antenna.

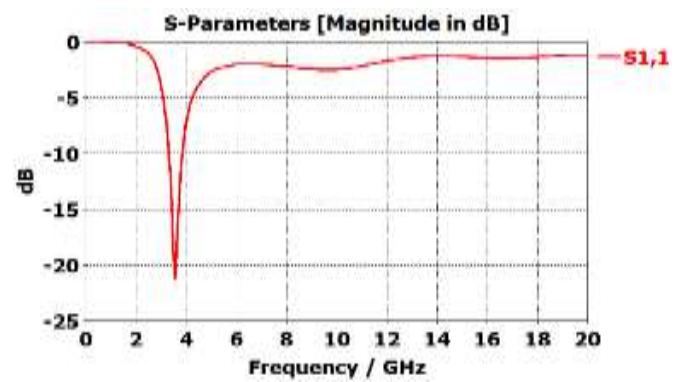

(a)

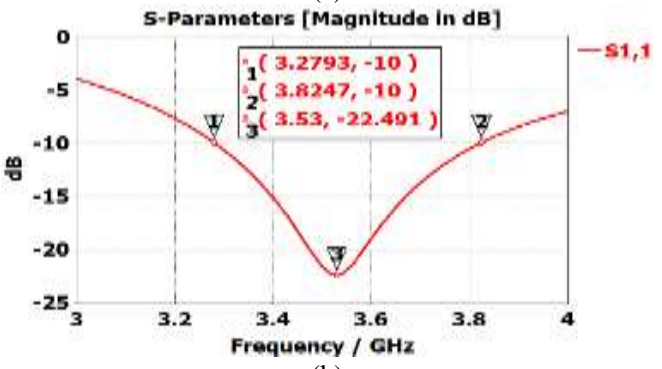

(b)

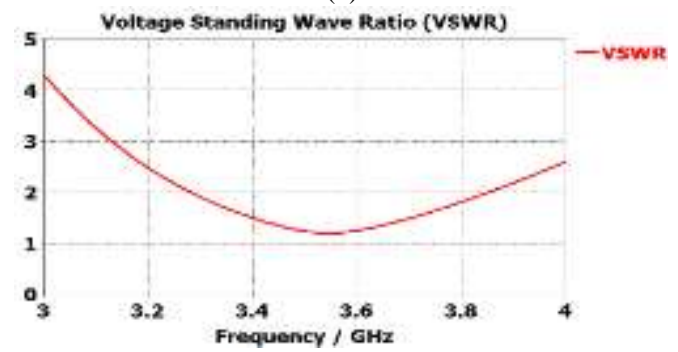

(c)

Fig. 4. Impedance Matching Responses of the Designed Antenna (a) $S_{11}$ in Wide-Span (b) $S_{11}$ in Narrow-Span (c) VSWR.

After the impedance matching quality of the antenna is observed, the next step is to check the radiation properties of the antenna. Fig. 5 presents a $3 \mathrm{D}$ and a $2 \mathrm{D}$ polar plot of the radiation pattern of the antenna, the realized gain, and the radiation efficiency of the antenna. As Fig. 5(a) illustrates the $3 \mathrm{D}$ radiation pattern of the antenna, it can be seen that the pattern is omni-directional with a maximum realized gain of $2.07 \mathrm{~dB}$ at the center frequency of $3.53 \mathrm{GHz}$. The omnidirectional radiation pattern can also be understood by looking at the E-plane and the H-plane responses of the antenna according to the 2D polar pattern depicted in Fig. 5(b). Because the E-plane exhibits nearly a circular while the $\mathrm{H}$ plane exhibits a bidirectional 2D patterns, the designed antenna offers a typical monopole omni-directional radiation pattern which is not just the most effective radiation for ambient RF energy harvesting but also efficient for many other applications like biomedical and sensor-based systems.

Fig. 6(c) shows realized gain of the antenna from 3 4 $\mathrm{GHz}$. The maximum realized gain is $2.07 \mathrm{~dB}$. Fig. 6(d) reveals the radiation efficiency of the antenna. The efficiency is very high throughout the whole bandwidth by reaching to $99.5 \%$, and it never goes below $98 \%$. Thus, these radiation parameters justify the quality of the designed antenna on the flexible substrate. To assess the antenna flexibility, the investigations on its bending ability has been performed. Here, two bent conditions with an angle of $90^{\circ}$ have been investigated using 
CST MWS: bending along width (Fig. 7(a)), and bending along length (Fig. 7(b)).

Fig. 6(c) summarizes the $S_{11}$ response and Fig. 6(d) summarizes the realized gain of the antenna for no bending, width-wise bending, and length-wise bending conditions. From the $S_{11}$ response for different bending conditions, it is seen that there is no change in the response for the length-wise bending, and it is fully overlapped with the response of the unbent condition. However, the width-wise bending condition gives a visible shift in the resonance, and a loss of $S_{11}$ value but it is still below $-17 \mathrm{~dB}$ while resonating around $3.51 \mathrm{GHz}$. Once again, it can be understood that the design is stable in terms of impedance matching. Fig. 6(d) presents the realized gain for different bending conditions. Here, the realized gain is dissimilar to the unbent condition $(2.07 \mathrm{~dB})$. For lengthwise bending and width-wise bending, the realized gain drops to $1.96 \mathrm{~dB}$ and $1.84 \mathrm{~dB}$, respectively. Nevertheless, such a range of realized gain is decently remarkable compared with other flexible antennas.

\section{B. Rectifier}

Because of the two tapered lines used at both terminals of the rectifier core, there have been some significant effects on the return loss, output DC voltage, and PCE of the rectifier. In Fig. 7, the minimum return loss is observed as $-28.91 \mathrm{~dB}$ at $3.5 \mathrm{GHz}$, and the $-10 \mathrm{~dB}$ bandwidth is seen as $80 \mathrm{MHz}$ which fits in the $5 \mathrm{G}$ band of Malaysia $(100 \mathrm{MHz} \mathrm{BW}$ at $3.5 \mathrm{GHz}$ center frequency).

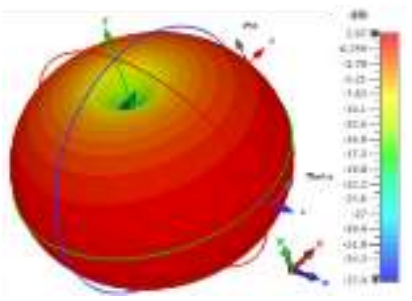

(a)

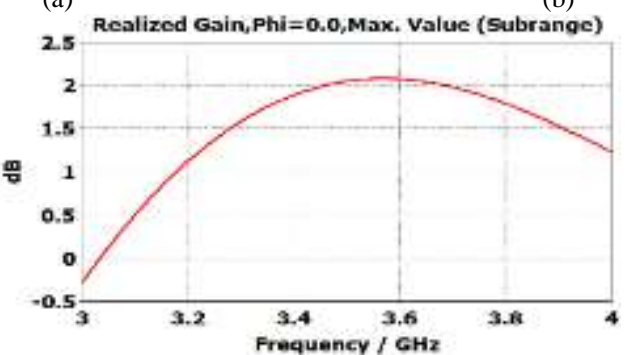

(c)

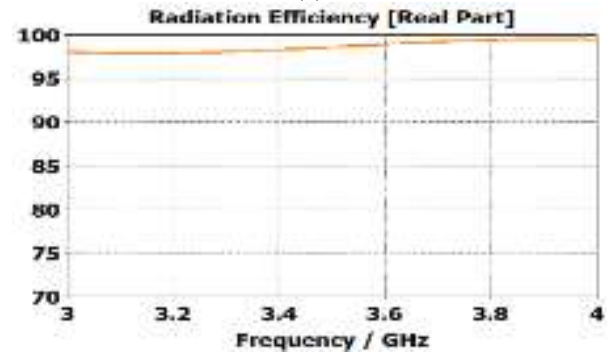

(d)

Fig. 5. Radiation properties (a) 3D pattern (b) 2D polar pattern (c) realized gain $(d)$ radiation efficiency

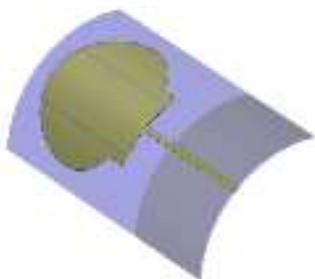

(a)

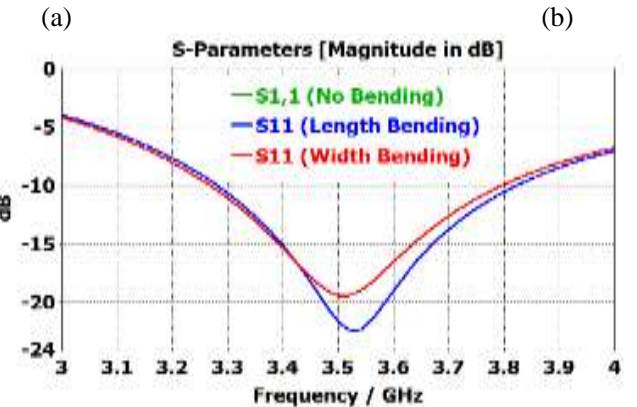

(c)

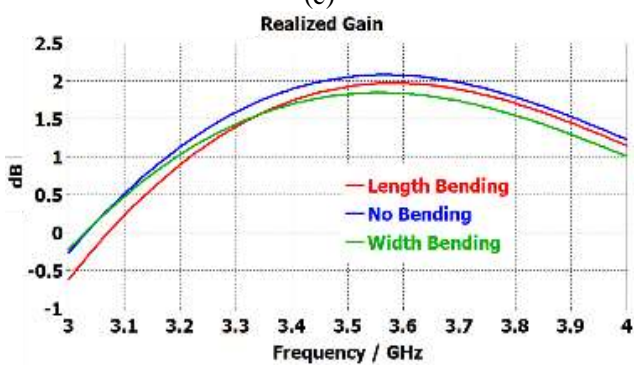

(d)

Fig. 6. Antenna in Flexibility (a) width-wise Bending (b) Length-wise Bending (c) effects on $\mathrm{S}_{11}$ (d) effects on Realized Gain Response.

In terms of different RF power delivered to the input terminal of the rectifier, changes of output DC voltage $\left(V_{\text {out }}\right)$ and PCE have been presented in Fig. 8.

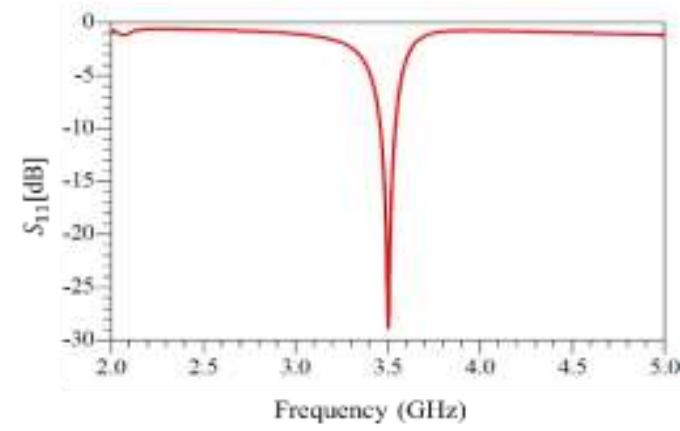

Fig. 7. Impedance Matching in $S_{11}$ of the Proposed Rectifier.

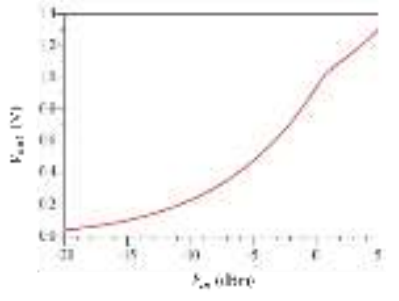

(a)

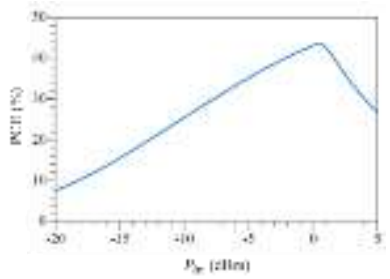

(b)
Fig. 8. Rectifier Response with different RF Power from Antenna (a) $V_{\text {out }}$ Change (b) PCE Change. 
According to Fig. 8(a), output DC voltage varies from 100 $\mathrm{mV}$ to $930 \mathrm{mV}$ while the RF power delivered to the input varies from $-15 \mathrm{dBm}$ to $0 \mathrm{dBm}$. For the same variation of $\mathrm{RF}$ power, PCE of the rectifier varies from $15.3 \%$ to $43.5 \%$. The highest PCE $(43.65 \%)$ is obtained when $0.5 \mathrm{dBm}$ RF power is delivered to the rectifier from the antenna. Although PCE starts decreasing with the increase of RF power, the output DC voltage continues to increase. However, most of the energy harvesting and sensor-based systems are not surrounded by high RF power in the environment. Therefore, it is better to achieve higher PCE for the lower RF power which is a remarkable aspect of the proposed rectifier.

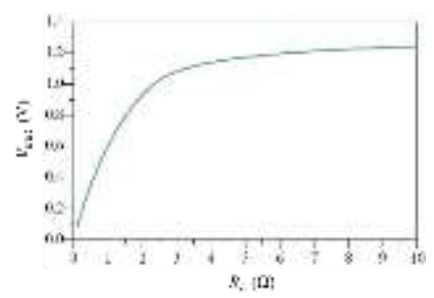

(a)

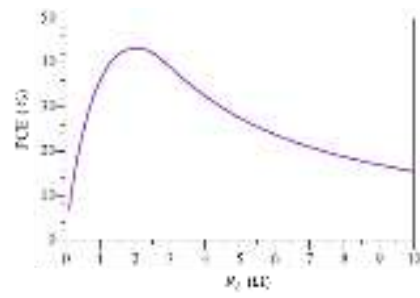

(b)
Fig. 9. Effects of Load Variation on (a) $V_{\text {out }}$ and (b) PCE for $0 \mathrm{dBm}$ RF.

Although the proposed rectifier is designed with $2 \mathrm{k} \Omega$ load resistor, load variation and its effects on output DC voltage and PCE are important to observe as illustrated in Fig. 9.

Output DC voltage remains quite stable $(930 \sim 1242 \mathrm{mV})$ within the range of $2 \sim 10 \mathrm{k} \Omega$ load variation when the antenna delivers $0 \mathrm{dBm}$ RF power to the rectifier. PCE gradually decreases with the increase of load resistances; yet PCE does not go below $15.45 \%$ even if the load resistance is increased to $10 \mathrm{k} \Omega$. The proposed rectifier occupies a small area of $29.6 \times$ $13.6 \mathrm{~mm}^{2}$.

\section{CONCLUSIONS}

A planar keyhole-shaped monopole antenna with partial ground plane has been designed, and its performance has been analyzed for $3.5 \mathrm{GHz}$. An omni-directional radiation pattern has been found which is suitable for the RF energy harvesting systems. The designed antenna has the maximum realized gain of $2.07 \mathrm{dBi}$ and the maximum efficiency of $99.5 \%$. A new RF rectifier has been introduced and then the antenna is integrated with it to construct a rectenna for the energy harvesting system. The proposed rectifier has the highest PCE of $43.65 \%$ when $0.5 \mathrm{dBm}$ RF power is delivered from the antenna. Apart from the $5 \mathrm{G}$ applicability, the designed antenna with the proposed rectifier can be efficiently applied in energy harvesting, biomedical and sensor-based systems.

\section{ACKNOWLEDGMENT}

This research is done in collaboration with, Universiti Teknikal Malaysia Melaka (UTeM), Melaka, Malaysia; Department of Electronics and Computer Engineering (ECE), International Islamic University Malaysia (IIUM) and Faculty of Information Science and Technology, University Kebangsaan Malaysia (UKM).

\section{REFERENCES}

[1] The Malaysian Communications and Multimedia Commission, "Final Report on Allocation of Spectrum Bands for Mobile Broadband Service in Malaysia" Jan 2020. Last accessed Sept 2020. Availabl at https://www.mcmc.gov.my/skmmgovmy/media/General/pdf/Final-

Report_Allocation-of-Spectrum-Bands-for-Mobile-Broadband-ServiceIn-Malaysia_20191231.pdf

[2] M. S. Islam, M. I. Ibrahimy, S. M. A. Motakabber, A. K. M. Z. Hossain, and S. M. K. Azam, "A wideband millimeter-wave printable antenna on flexible substrate for breast cancer imaging," presented at the 2019 7th International Conference on Mechatronics Engineering (ICOM), Putrajaya, 2019, Accessed: Dec. 23, 2019. [Online]. Available: http://www.iium.edu.my/icom/programme.pdf.

[3] K. D. Song, T. B. Stout, S. Yang, J. Kim, and S. H. Choi, "Energy harvesting of dipole rectenna for airship applications," in Nanosensors, Microsensors, and Biosensors and Systems 2007, Apr. 2007, vol. 6528, p. $65280 \mathrm{~K}$, doi: $10.1117 / 12.721765$.

[4] I. Kharrat, P. Xavier, T.-P. Vuong, and G. E. P. Tourtollet, "Compact Rectenna Design for Lossy Paper Substrate at $2.45 \mathrm{GHz}$," Progress In Electromagnetics Research, vol. 62, pp. 61-70, 2016, doi: 10.2528/PIERC15093005.

[5] H. Dong, X. Hou, Q. Zhang, and F. Wang, "Flexible slot-ring antenna for RF wireless energy harvesting," in 2018 International Workshop on Antenna Technology (iWAT), Mar. 2018, pp. 1-4, doi: 10.1109/IWAT.2018.8379233.

[6] S. M. K. Azam, M. S. Islam, A. K. M. Z. Hossain, and M. Othman, "Monopole Antenna on Transparent Substrate and Rectifier for Energy Harvesting Applications in 5G," International Journal of Advanced Computer Science and Applications (IJACSA), vol. 11, no. 8, Art. no. 8, 31 2020, doi: 10.14569/IJACSA.2020.0110812.

[7] S. Bellal, H. Takhedmit, and L. Cirio, "Design and experiments of transparent rectennas for wireless power harvesting," in 2016 IEEE Wireless Power Transfer Conference (WPTC), 2016, pp. 1-4.

[8] Bouchouicha, D., Dupont, F., Latrach, M., \& Ventura, L. (2010). Ambient RF energy harvesting. Renewable Energy and Power Quality Journal, 1(8), 1309-1313. doi:10.24084/repqj08.652.

[9] Pandey, R., Shankhwar, A. K., \& Singh, A. (2020). Defected ground structured wideband antenna for RF energy harvesting. Paper presented at the Proceedings of the 4th International Conference on Trends in Electronics and Informatics, ICOEI 2020, 288-291. doi:10.1109/ICOEI48184.2020.9142951.

[10] M. S. Islam, M. I. Ibrahimy, S. M. A. Motakabber, A. K. M. Z. Hossain, and S. M. K. Azam, "Microstrip patch antenna with defected ground structure for biomedical application," Bulletin of Electrical Engineering and Informatics, vol. 8, no. 2, pp. 586-595, Jun. 2019, doi: 10.11591/eei.v8i2.1495.

[11] M. S. Islam, M. I. Ibrahimy, S. M. A. Motakabber, and A. K. M. Z. Hossain, "A Rectangular Inset-Fed Patch Antenna with Defected Ground Structure for ISM Band," in 2018 7th International Conference on Computer and Communication Engineering (ICCCE), Sep. 2018, pp. 104-108, doi: 10.1109/ICCCE.2018.8539260.

[12] C. A. Balanis, Antenna Theory: Analysis and Design. John Wiley \& Sons, 2016.

[13] S. M. K. Azam, M. I. Ibrahimy, S. M. A. Motakabber, and A. K. M. Z. Hossain, "Plans for Planar: Phase-Noise Reduction Techniques in Voltage-Controlled Oscillators," IEEE Microwave Magazine, vol. 20, no. 11, pp. 92-108, Nov. 2019, doi: 10.1109/MMM.2019.2935364.

[14] S. M. K. Azam, M. I. Ibrahimy, S. M. A. Motakabber, A. K. M. Z. Hossain, and M. S. Islam, "A miniaturized hairpin resonator for the high selectivity of WLAN bandwidth," Bulletin of Electrical Engineering and Informatics, vol. 8, no. 3, pp. 916-922, Sep. 2019, doi: 10.11591/eei.v8i3.1496. 